\title{
O tema Sexualidade Humana no ensino médio: as Ilhas Interdisciplinares de Racionalidade como metodologia em aulas de biologia
}

Ana Maria Quinoto Imhof anamariaimhof@gmail.com 0000-0003-3802-5679 Blumenau, Santa Catarina, Brasil.

\section{Edson Schroeder} ciência.edson@gmail.com

de Blumenau, Blumenau, Santa Catarina, Brasil.

\section{RESUMO}

Este trabalho objetivou identificar as contribuições da metodologia IIR no processo de alfabetização científica a partir do estudo do tema Sexualidade Humana por estudantes do ensino médio, em uma escola pública de Brusque (SC). As aulas foram gravadas em vídeo, posteriormente analisadas. Os resultados mostraram que os alunos se sentiram motivados para a construção dos seus modelos explicativos, resultante da reflexão, da utilização da escrita e da participação conjunta com seus pares. Entende-se que a IIR pode trazer contribuições para a aprendizagem de biologia, tendo-se como expectativa a alfabetização científica dos alunos.
\end{abstract}

PALAVRAS-CHAVE: Ensino de biologia. Sexualidade. Interdisciplinaridade. 


\section{INTRODUÇÃO}

Dados divulgados pelo PISA, em 2010, mostram que houve um crescimento no desempenho das provas por parte dos alunos, entretanto, ainda não há razões para comemoração. O maior desafio não é aumentar a pontuação das notas mas mantê-las no patamar conquistado. Para isso, são necessárias mudanças e, segundo documentos oficiais e programas relativos à Educação Básica de outros países, recomenda-se a substituição de práticas educativas centradas no ensino disciplinar e no modelo transmissão-recepção, pela implementação de uma prática centrada no aluno mais participativo e no desenvolvimento de competências (BRASIL, 2002; 1998). Defende-se que o ensino seja mais contextualizado e interdisciplinar.

Frente à realidade exposta, Fourez (1995) apresenta estratégias de ensino que viabilizam a alfabetização científica pelo desenvolvimento de projetos interdisciplinares, denominadas Ilhas de Racionalidade (IR), considerando alfabetizado tecnológica e cientificamente, o cidadão que possua "autonomia (possibilidade de negociar suas decisões perante as pressões naturais e sociais), capacidade de comunicar (encontrar maneiras de dizer) e relativo domínio e responsabilidade, frente a uma situação concreta" (FOUREZ, 1997, p. 51). A proposta do autor, com foco centrado na realidade dos alunos, transforma a maneira de atuação do professor, uma vez que permeia no ambiente escolar uma visão inadequada do conhecimento científico e suas aplicações. Os envolvidos passam a compreender que os conhecimentos resultam das interações do homem com suas necessidades e contextos específicos e que os avanços científicos e tecnológicos alcançados resultam de um momento histórico e suas demandas.

A metodologia IR tem como intuito promover um ensino baseado não na lógica disciplinar e na transmissão-recepção, mas na participação do aluno, levando-se em consideração suas necessidades. Neste sentido, o que se pretende é promover alfabetização científica, levando-o a pensar sobre questões cada vez mais complexas e contextualizadas, na medida em que o ensino avança. No processo, concebe-se que os avanços científicos são necessários para atender às necessidades do homem, que em ciência não há verdades absolutas e que os modelos desenvolvidos são utilizados enquanto potenciais explicativos dos fenômenos naturais. Fourez (1997) preceitua um conjunto de etapas e apresenta as implicações da sua aplicação em sala de aula. Basicamente, a metodologia valoriza o trabalho em equipe e visa o incremento de conexões com outras disciplinas. Como resultado, pretende-se a construção, pelos alunos, de um modelo simples, mas que expresse as suas aprendizagens.

Gérard Fourez, físico e professor, utiliza o conceito Ilha de Racionalidade para designar um modelo. Quando esse modelo ou representação necessita consultar diversas disciplinas ou diferentes domínios de conhecimento passa-se a usar a expressão Ilhas Interdisciplinares de Racionalidade (IIR), termo que será utilizado doravante. A construção de uma IIR situa-se mais no plano epistemológico e está ligada a uma atividade de pesquisa em que cada disciplina conserva a sua especificidade. Maingain e Dufour (2008, p. 74) esclarecem que, nessa perspectiva: 
A abordagem interdisciplinar, de acordo com os autores, vem contribuir no sentido de ampliar os conhecimentos, muitas vezes exigidos para a resolução de problemas escolares ou da vida particular. As conexões e interseções, nas diferentes áreas do conhecimento, podem contribuir para aprendizagens conceituais, para diminuição de muitos preconceitos e para uma finalidade particular. Nas páginas a seguir, caracterizamos a alfabetização científica e a metodologia IIR, os contextos da pesquisa e os sujeitos participantes, além do registro e resultados da aplicação da metodologia em aulas de biologia, a partir do desenvolvimento tema Sexualidade Humana com alunos do ensino médio em uma escola pública estadual, no município de Brusque (SC), tratando-se de uma pesquisa participante, cujos resultados fizeram parte de uma dissertação de Mestrado Profissional.

\section{A ALFABETIZAÇÃo CIENTÍFICA EM SALA DE AULA}

O termo alfabetização refere-se originalmente à língua escrita e à cultura letrada, baseada na capacidade de ler e escrever e ambas estão na base da educação escolar. E as definições sobre alfabetização são quase tão numerosas quanto os autores que já se ocuparam do tema, no entanto, a partir de 1950 houve um consenso sobre o que é alfabetização. Coll e Monereo (2010, p.29) consideram que "uma pessoa alcançou um nível de alfabetização funcional quando adquiriu o conhecimento e habilidades de leitura e escrita que a capacitam para envolver-se em atividades mediadas pelos textos escritos habituais em sua cultura ou em seu grupo social". Com a evolução social, científica e tecnológica, a alfabetização passou a ter denominações mais específicas: alfabetização tecnológica, alfabetização econômica, alfabetização ambiental e alfabetização científica.

No início do século XX, a alfabetização científica começou a ser debatida mais intensamente. Neste sentido, pode-se destacar o trabalho de John Dewey, que já defendia, nos Estados Unidos, a sua importância, uma vez que se produzia muita tecnologia, mas seu uso, produção e impactos ambientais eram desconhecidos por grande parte da população. Muitos estudos passaram a ser mais significativos nos anos de 1950, em pleno período do movimento cientificista, em que se atribuía uma supervalorização ao domínio do conhecimento científico em relação às demais áreas do conhecimento humano. A temática tornou-se um grande slogan, surgindo um movimento mundial em defesa da educação científica (SANTOS, 2007).

Contudo, alguns autores problematizam a conveniência da alfabetização científica, inclusive a possibilidade da generalidade de cidadãos e cidadãs adquirirem uma formação científica realmente útil para, entre outros objetivos, participarem na tomada de decisões (ATKIN; HELMS, 1993; SHAMOS, 1995; FENSHAM, 2002; VILCHES; SOLBES; GIL-PÉREZ, 2004). Trata-se de trabalhos bem documentados que pretendem "abalar aparentes evidências", como seria, em suas opiniões, a necessidade de alfabetizar cientificamente toda a população, algo que Shamos (1995) classifica como um autêntico mito, no seu livro The myth of 
é preciso analisar com mais cuidado os argumentos dos autores citados. Santos (2007, p.479) defende a alfabetização científica quando considera:

\begin{abstract}
que um cidadão 'letrado' não apenas sabe ler o vocabulário científico, mas é capaz de conversar, discutir, ler e escrever coerentemente em um contexto não-técnico, mas de forma significativa. Isso envolve a compreensão do impacto da ciência e da tecnologia sobre a sociedade em uma dimensão voltada para a compreensão pública da ciência dentro do propósito da educação básica de formação para a cidadania.
\end{abstract}

Fourez evidencia a importância do cidadão ser autônomo para tomar as decisões, defendê-las e responsabilizar-se pelas mesmas. Fourez compreende na alfabetização científica a expressão de finalidades humanistas, sociais e econômicas. No Brasil, apesar de estarmos aquém do estágio já alcançado pelos países desenvolvidos nos aspectos culturais, científicos e tecnológicos, urge a necessidade de lançarmos as "sementes" da alfabetização científica. Com isto, pretende-se transformar os conhecimentos produzidos pela ciência e pela tecnologia em conceitos que possam ser compreendidos pelos jovens, para que conquistem estágios mais sofisticados de conhecimento, com vistas à autonomia, criticidade, ética e participação social.

\title{
ILHAS DE RACIONALIDADE: DEFINIÇÃO E CARACTERIZAÇÃO
}

Gérard Fourez utiliza o conceito Ilha de Racionalidade para designar uma modelização. A expressão baseia-se na metáfora de uma ilha de conhecimentos que a propósito de um assunto determinado, emerge de um oceano de ignorância (FOUREZ, 1997). O termo racionalidade remete ao fato dessa representação permitir a discussão racional da situação envolvida, isto é, com conhecimento de causa e segundo certas convenções negociadas. Em outras palavras, uma representação racionalizada permite evitar um diálogo de surdos (FOUREZ, 1995, 2003).

A interdisciplinaridade possibilita a organização de uma representação, em função de uma intenção prévia, muitas vezes, negociada entre os diferentes atores. Construir uma representação interdisciplinar exige uma aptidão para ultrapassar as fronteiras disciplinares e para praticar certas formas de integração ou de articulação das disciplinas entre si. De acordo com Marinho (2004, p. 51) "a interdisciplinaridade representa uma forma de convivência das disciplinas sem, contudo, haver perda das especificidades de cada conteúdo". Ou seja, significa o desejável e necessário estabelecimento de convivência entre disciplinas diferentes sem que haja o prejuízo de suas identidades. Não é possível ignorar que, para que haja interdisciplinaridade é preciso que as disciplinas estejam constituídas.

Na construção de uma IIR, cada disciplina conserva a sua especificidade. É mesmo oportuno, tanto do ponto de vista epistemológico como pragmático, que cada especialista reconheça o estatuto, as vantagens e os limites do seu campo, no que diz respeito a outras disciplinas. Em contrapartida, o que decorre de cada uma é uma representação que é negociada no processo interdisciplinar. A principal diferença entre uma abordagem disciplinar e uma abordagem interdisciplinar é que a primeira "produz ou mobiliza saberes e experiências, em função do paradigma da disciplina envolvida, enquanto a segunda produz ou mobiliza conhecimentos e competências estruturados em função de uma situação precisa 
e de uma finalidade particular (MAINGAIN; DUFOUR, 2008, p. 74). A construção de uma IIR utiliza a estratégia de percurso, definida por Maingain e Dufour (2008, p. 120) como:

um conjunto dinâmico de sequências sucessivas, articulando diversos objetos de investigação e diversas tarefas de aprendizagem em função de objetivos pedagógicos (de ordem cognitiva, metodológica, cultural) um percurso pode culminar na realização pelos alunos de uma produção sociável.

A estratégia pedagógica de uma IIR pode ser definida por um professor ou uma equipe de professores levando em conta os seguintes questionamentos: ensinar para que alunos? Com que objetivos, em particular, para alcançar que competências disciplinares, interdisciplinares ou transdisciplinares? Com que representação(ões) global(ais) do projeto a realizar, do objeto a estudar, da situação a ser resolvida? De acordo com que sequências? Com que articulações entre elas? Com que conteúdos disciplinares? Com que interações entre esses? Com que pessoas e recursos? Segundo que programação? Em que prazos? Quantas horas-aula seriam necessárias investir? Em vista de que eventuais produções? Com que modalidades de avaliação?

Para que possamos concretizar uma alfabetização científica, processo em que a dimensão interdisciplinar é muito importante, faz-se necessário romper com paradigmas, quebrar muros. Além disto, necessitamos substituir o conformismo pelo inconformismo, abrir-se para incertezas, mudar a forma de ensinar, romper com o modelo de ensino baseado na transmissão-recepção. Neste sentido, no Brasil, necessitamos repensar a organização tradicional do ensino médio, sobretudo no que diz respeito à compartimentalização dos saberes, para alcançarmos os objetivos da educação básica: formar um cidadão com compreensão global das situações, ser um autor social, autônomo e crítico (BRASIL, 1998).

A metodologia IIR alcança seus objetivos quando a(s) situação(ões) problema(s) fazem parte do contexto do aluno e este o(s) percebe como um problema. Cabe ao professor ou à equipe de professores, e até mesmo os alunos, identificar uma situação problema contextualizada e que possibilite a inserção de diferentes áreas do conhecimento na sua resolução.

\section{AS ETAPAS PARA A IMPLEMENTAÇÃO DA METODOLOGIA IIR}

Fourez propõe um conjunto de etapas que caracterizam a proposta metodológica:

1. Etapa zero - a decisão da aplicação da metodologia IIR conduz o professor e sua equipe a um levantamento dos recursos necessários à realização das atividades. De acordo com Schmitz (2004) esta preocupação diminui as frustrações ou as situações de improviso. Fourez (1997) apresenta uma classificação para os recursos: humanos (professores, alunos, especialistas e comunidade) e materiais (biblioteca, internet, vídeos, laboratórios). Em aulas consideradas tradicionais é o professor que planeja e elabora as atividades, seguindo de maneira linear a execução das mesmas e definindo a importância dos objetos do conhecimento. Na 
que identificam o que é importante aprender. Cabe ao professor organizar os conteúdos, os recursos humanos e materiais.

Após o levantamento dos recursos, dos especialistas, dos objetivos e o público alvo definidos, dá-se início à etapa de implementação da metodologia. Segundo Fourez (1997) o sucesso na execução da proposta IIR depende da capacidade do professor negociar as relações entre os objetivos da proposta e aqueles da disciplina específica. A sua aplicação não abandona as práticas disciplinares, mas procura cruzar as diversas áreas do conhecimento, cada qual com suas particularidades e importância, mobilizando os conhecimentos para situações particulares.

Uma vez definido o objeto de estudo e público alvo, faz-se o sequenciamento das etapas associadas à metodologia: clichê, panorama espontâneo, consulta a especialistas, indo à prática, abertura de caixas pretas, esquematizando a situação problema, abrindo caixas pretas sem especialistas, o produto final. Quem define a duração de cada uma das etapas descritas a seguir é o professor ou a equipe envolvida. O tempo disponibilizado para cada uma se dá em função de objetivos e possibilidades. Na prática, não se trabalha de maneira linear, mas com idas e voltas e o resultado de uma etapa pode conduzir a outra precedente.

2. Clichê da técnica estudada - por clichê entende-se um conjunto de representações (corretas ou errôneas) que uma investigação tem de uma técnica. Trata-se de dar uma descrição espontânea (conhecimentos prévios para a investigação). Para isto, pode-se questionar em um contexto brainstorming, partindo-se de questões mais gerais ou mais precisas. Ela reflete o que pensa um grupo, mesmo sem formação especial. Durante, ou antes, da investigação, é interessante distinguir o que é admitido por todos, o que é objeto de debate e o qual o juízo de valor a respeito.

3. Panorama espontâneo - trata-se de expandir o contexto do clichê. Essa etapa é ainda bastante espontânea, na medida em que ela não envolve um especialista, entretanto, pode-se organizar uma lista de especialistas como professores, artistas, psicólogos, etc. Na etapa do panorama espontâneo, organiza-se uma lista de posturas e tensões sobre as vantagens e inconvenientes em se aprofundar determinados temas. A seguir, apresentamos uma sequência de subetapas que caracterizam o panorama espontâneo:

a) lista de posturas e tensões: quais são as vantagens e inconvenientes de uma técnica? Que valores são buscados e que efeitos se objetiva com essa busca? Quais as vantagens de conhecer a fisiologia da reprodução? Quais são as vantagens e inconvenientes de discutir sexualidade? Quais são os valores e o que se discute?

b) lista das caixas pretas: organiza-se uma lista de conceitos ou matérias passíveis de um estudo que poderão ser aprofundados, ou não. As caixas pretas designam temas potenciais sujeitos à pesquisa (entre os quais se elegerá os mais importantes e do interesse dos alunos). Por exemplo: um adolescente quer estudar como se prevenir das doenças sexualmente transmissíveis ou uma pessoa com vírus do HIV quer estudar como poderia conviver melhor com a doença. O termo trata de uma representação de uma parte do mundo do aluno, sem considerar a validade de se analisar os mecanismos de sua operação - pode-se utilizar a noção de vírus para falar de uma série de enfermidades contagiosas sem se preocupar 
c) lista de bifurcações: uma bifurcação corresponde, frequentemente, a uma postura, designa um momento em que o ator social - por exemplo um professor, um vendedor, um usuário é levado a eleger uma estratégia. Muitas dessas seleções são técnicas, mas algumas possuem uma dimensão ética (inclusive política).

d) lista de especialidades e especialistas envolvidos: as caixas pretas que serão abertas podem exigir um determinado tipo de especialista. Cada um tem uma noção sobre sexualidade e são os especialistas que irão ajustar as representações frágeis ou até mesmo equivocadas. Os especialistas são considerados em relação a uma especialidade intelectual ou em relação a uma profissão reconhecida. A lista de especialista será feita de acordo com cada IR e de acordo com o contexto. Da lista produzida anteriormente se selecionará para a consulta uma ou outra especialidade, a mesma das caixas pretas que serão abertas em função do projeto. A consulta a especialistas tem uma dupla função: em princípio, responder às questões sobre a sexualidade, além da possibilidade da abertura de outras caixas pretas.

4. Consulta aos especialistas envolvidos - nessa etapa, se elege um especialista que se quer consultar. Dois tipos de critérios são preponderantes: a situação e projeto selecionado e os objetivos escolares (noções científicas importantes a dominar e definidas pelo programa). A consulta ao especialista vincula-se à abertura subsequente de uma caixa preta.

5. A prática - ir à prática é abandonar o contexto teórico, para ir em direção a um contexto relacionado ao cotidiano. Há diversas maneiras de se proceder. Por exemplo, pode-se conhecer, por intermédio da arte, as percepções sobre o corpo em um tempo histórico, ou pela biologia, como utilizar métodos contraceptivos, conhecer melhor as etapas da fecundação. Fourez (1997) destaca que a ida à prática depende dos objetivos do projeto e dos envolvidos.

6. Abertura aprofundada de uma ou outra caixa-preta e a descoberta dos "princípios disciplinares" que sustentam uma tecnologia - para Fourez (1997, p. 118) "esta etapa é fundamental para aprofundar um ou outro aspecto do objeto estudado, com aporte do rigor de uma disciplina científica". A abertura de uma caixa preta pode levar, paralelamente, à abertura de outras caixas, com diferentes graus de profundidade, de acordo com a capacidade de aprendizagem do aluno. Ao final da consulta ao especialista, pode-se solicitar a representação de um modelo simples, como construir um cartaz, escrever um texto ou fazer um desenho.

7. Esquematização global de uma tecnologia - essa etapa consiste, especialmente, na elaboração de uma ficha projetada do objeto, ou um esquema da organização social de uma tecnologia: é uma síntese parcial e objetiva da IIR.

8. Abertura de caixas pretas sem a ajuda de especialistas - na vida, nem sempre dispomos de especialistas e de saberes desejados e adequados para resolver uma situação particular. Segundo Fourez (1997), em alguns momentos, é necessário agir e construir modelos mais esclarecedores. Cabe, nessas situações, a consulta a fontes como livros, revistas, internet, já que os especialistas não podem estar presentes para responder a todas as questões levantadas. A construção de modelos com os meios disponíveis pode ter um efeito educativo importante, na medida em que se reproduzem as situações da vida cotidiana, nas quais se devem tomar decisões concretas. 
9. Síntese da IIR (o produto final) - nessa última etapa, pode-se sintetizar, seja oralmente, seja em uma nota escrita, a IIR que se construiu em função do projeto. Essa é uma síntese em que, frequentemente, se cruza com elementos muito variados. Inclusive há certas perguntas que são particularmente pertinentes: em que medida o que se tem estudado ajuda a negociar com as tecnologias enfocadas? Em que medida amplia a autonomia no mundo do qual eu faço parte? De que forma os saberes obtidos contribuem para as decisões mais adequadas? De que maneira o conteúdo abordado fornece uma representação do mundo e da história dos integrantes do grupo e permite-lhes se situar e se comunicar melhor com os outros? De acordo com Maingain e Dufour (2008, p. 120): “o percurso não tem necessariamente, de comportar uma produção final ou uma produção de grande envergadura. Pode-se tratar de produções mais modestas nas diferentes fases do percurso, permitindo verificar o domínio das aprendizagens". Portanto, o produto a ser construído pelos alunos pode ser simples, mas poderia contemplar algumas dessas questões, não sendo necessária uma produção de grande envergadura, permitindo verificar o domínio de aprendizagens pertinentes ao contexto e o aprendizado de conceitos da biologia. $\mathrm{O}$ fato poderá possibilitar a percepção do mundo de forma mais simplificada em função da construção de uma representação da situação problema.

\section{OS CONTEXTOS DA PESQUISA E OS SUJEITOS PARTICIPANTES}

A pesquisa aconteceu em uma escola de educação básica, localizada no centro da cidade de Brusque (SC), tendo-se a seguinte questão central: quais as contribuições da metodologia IIR para o processo de alfabetização científica, no desenvolvimento do tema Sexualidade Humana? Entre os objetivos definidos, pretendia-se adaptar para as aulas de biologia, as etapas propostas por Fourez, com vistas ao incentivo à autonomia, ao trabalho em equipe e à resolução de situações problema.

A primeira série do ensino médio, alvo da pesquisa, era formada inicialmente por 38 alunos (24 meninas e 14 meninos) com média etária de 15 anos. Os alunos pertenciam a famílias de classe média, compostas por três a cinco pessoas, que utilizam a televisão como principal fonte de informação. O desenvolvimento da pesquisa aconteceu em 16 encontros, em aulas geminadas de biologia. A professora que desencadeou o processo também foi a pesquisadora. Neste sentido, tratou-se de uma pesquisa participante, levando-se em consideração procedimentos que buscam encontrar alternativas para a resolução de problemas reais em coletividade, estabelecendo etapas para considerar e analisar os efeitos, os riscos, a resolução dos desafios.

Foram três os requisitos, considerados importantes e necessários para compreender melhor os mecanismos associados ao processo de aprendizagem nas aulas de biologia: a observação da interação que se estabeleceu entre alunos e a professora, com atenção aos aspectos relativos à utilização da linguagem científica; a observação de como os processos de realização das tarefas evoluíram e a utilização dos conceitos sobre sexualidade humana em diferentes contextos. As aulas foram gravadas em vídeo e os dados submetidos à análise, objetivandose um exame das transformações que se efetivaram no decorrer do processo. Outra importante fonte de informações foram as produções elaboradas pelos alunos no transcorrer das aulas. No procedimento de análise das aulas, colocou-se 
em evidência alguns indicadores de desenvolvimento considerados importantes: os diálogos que se estabeleceram entre os envolvidos; os questionamentos e sua natureza; a produção acadêmica individual e coletiva, concretizada em cartazes, textos e vídeos, além do emprego dos conceitos científicos nos diferentes contextos.

\section{IIR: O TEMA SEXUALIDADE HUMANA EM SALA DE AULA}

O tema escolhido, sexualidade humana, é polêmico e muitos professores sentem dificuldades em abordá-lo durante as aulas, conforme Sayão (1997). Essa dificuldade está associada à formação de cada pessoa e pode ser de cunho cultural. Tal tema é sugerido como tema transversal pelos Parâmetros Curriculares Nacionais (PCN) por ser relevante, desafiador. Conduzido de forma positiva pode promover a autoestima dos alunos, muitas vezes abalada no início e decorrer da adolescência, conforme Sayão (1997), Figueiró (2001) e Egypto (2003). Ignorar o tema é não atentar para questões cruciais como a iniciação sexual e gravidez não planejada. Essa iniciação pode conduzir, também, a um aumento de doenças sexualmente transmissíveis, conforme dados fornecidos pelo Ministério da Saúde (http://portal.saude.gov.br/portal/saude/). A escola de educação básica onde a pesquisa foi realizada se enquadra nesse contexto. Em função da complexidade do assunto e da situação, partiu-se das seguintes questões: o que é sexualidade? 0 que isso implica? Quais os conceitos que os adolescentes têm sobre a questão? Após a definição de uma situação problema, iniciou-se o que se denomina de etapa de planejamento ou etapa zero, período de investigação dos recursos disponíveis.

1. Etapa zero - é o período de "germinação da semente" da metodologia IIR. Para isso fez-se um levantamento dos recursos humanos e materiais disponíveis para desenvolvimento do tema escolhido. Nessa etapa, entrou-se em contato com alguns especialistas que poderiam fazer parte do projeto. Em um primeiro momento, planejou-se convidar diferentes especialistas para participarem do projeto: um médico (clínico geral), uma enfermeira, que trabalhou muito anos como apoio de parto, um farmacêutico, para fazer esclarecimentos sobre anticoncepcionais, a professora de história (que não se sentiu à vontade em trabalhar a sexualidade em diferentes culturas), a professora titular de artes (também preferiu não fazer parte dos especialistas). Em função das resistências e dificuldades para participação, cabe ao professor selecionar que tipos de caixas pretas poderiam ser abertas, levando em consideração a disponibilidade de especialistas.

Os recursos materiais disponíveis foram levantados com dois meses de antecedência ao projeto, pois era importante conhecer que tipo de materiais a escola poderia oferecer. Para isso, entrou-se em contato com a responsável pela biblioteca para verificar a disponibilidade de cartazes, livros, vídeos e revistas, caso fosse necessário consultar esses recursos. Foi organizado um espaço para que, no caso da falta da pessoa responsável pela biblioteca, o material fosse acessado com facilidade. Juntamente com o professor de informática, verificou-se a possibilidade de usar os computadores com acesso à internet e a sala de projeção de multimídia, mediante agendamentos prévios.

Uma vez levantados os recursos humanos e materiais, apresentou-se a intenção à direção da escola em uma reunião, que contou com a participação da 
direção, assessores de direção e a assistente pedagógica. Após a apresentação do projeto, foi solicitado permissão à equipe para o seu desenvolvimento na primeira série "I". A intenção era iniciar no mês de setembro, com cerca de 14 a 16 encontros.

Ao final do mês de agosto, apresentou-se aos alunos a intenção de desenvolver a proposta IIR: "Abrindo caixas pretas sobre a sexualidade humana". Houve clareza quanto à tratar-se do desenvolvimento de uma pesquisa de mestrado. Na oportunidade, o projeto foi caracterizado, seus objetivos demarcados e os conceitos relacionados à metodologia, definidos.

Para que a proposta pudesse ser desenvolvida, seria necessário o consentimento dos pais, para tanto, seria indispensável que assinassem um termo de consentimento entregue a todos os presentes naquele momento. Explicou-se aos alunos, que haviam estudado no bimestre anterior temas como a divisão celular, mitose e meiose, que o próximo tema trataria de assuntos relacionados com a reprodução, gravidez, doenças sexualmente transmissíveis, métodos contraceptivos. Na sequência foram desafiados com um problema real na escola: anualmente, muitas alunas acabam abandonando os estudos, pois ficam grávidas, outros por estarem doentes, uma vez que se iniciaram sexualmente sem ter conhecimento de como se prevenir. Neste sentido, à escola e a equipe dos professores cabe o papel fundamental de desenvolver, via alfabetização científica, uma ação educativa reflexiva e crítica. De acordo com os PCN (BRASIL, 1998, p. 292):

Queira ou não, a escola intervém de várias formas, embora nem sempre tenha consciência disso e nem sempre acolha as questões dos adolescentes [...]. A escola pode ter papel importante na educação para uma sexualidade ligada à vida, à saúde, ao prazer e ao bem-estar e que englobe as diversas dimensões do ser humano.

A partir dessas ponderações, seguiu-se a etapa seguinte da metodologia IIR, que trata do clichê. A questão norteadora inicial, feita à turma foi a seguinte: o que é sexualidade para você?

2. Clichê - para iniciar a etapa, foi entregue uma tira de papel para os alunos responderem, individual e anonimamente, o que o termo sexualidade representava para eles. Notou-se que não estavam acostumados a formularem conceitos próprios e a resistência, no primeiro momento, gerou desconforto, conforme pode ser ilustrado pelo questionamento de um aluno: "O que minha mãe vai pensar se ler o que eu escrevi"? A seguir, alguns conceitos sobre sexualidade: "Sexo, prazer, procriação, amor, homem e mulher." "Eu penso que sexualidade não é nada mais do que sexo, se você é homem, mulher ou até mesmo homossexual, nos órgãos sexuais femininos e masculinos." Os conhecimentos do senso comum sobre a sexualidade humana são produtos culturalmente compartilhados, portanto, fazem parte das representações de cada indivíduo. Cientes da carência de informações adequadas, os alunos as buscam, principalmente, entre seus pares, grande parte das vezes influenciadas pelas mídias que não estão efetivamente comprometidas com a alfabetização científica da população.

Na aula seguinte, a classe foi organizada em grupos espontâneos de quatro a posteriormente, construíssem um conceito em consenso. Notou-se que houve 
certa resistência na formação dos grupos, bem como constrangimento na defesa de conceitos entre os pares. Como resultado dessa etapa, apresentamos uma concepção', agora socializada com toda a turma:

Sexualidade nós achamos que é o feminino ou masculino, muitas pessoas levam o sexo adiante para se prostituir ou fazer filmes pornô, tiram a roupa só para aparecer e ganhar dinheiro mostrando seu corpo. Será que vale a pena? E também é quando duas ou mais pessoas se sentem atraídas umas pelas outras, ou seja desejo de possuir a pessoa[YASMIM, GIOVANA, HERCULES, CARLOS, JOAQUIM].

Após as apresentações, a discussão foi encerrada com um conceito de sexualidade, apresentado no livro "Juventude e sexualidade" (CASTRO; ABRAMOMOVAY; SILVA, 2004). A escolha pelo conceito, baseou-se pela clareza e cientificidade, apresentada pelos autores. Tentou-se deixar claro que a sexualidade diz respeito a uma dimensão humana muito mais ampla do que simplesmente o sexo, ou o ato sexual e envolve nossa história e nossa cultura (Egypto, 2003). Dependendo do contexto em que se vive, diferentes concepções sobre o sexo, bem como sobre a sexualidade são construídas. Para complementar a etapa 'clichê' foi solicitado que trouxessem imagens representativas da sexualidade, de acordo com os conceitos construídos. No encontro seguinte, a organização ocorreu em grupos de oito alunos. A tarefa seria elaborar um cartaz com as imagens trazidas e deveria exprimir um conceito de sexualidade. O grupo optaria por imagens que fossem consensuais e a escolha justificada para todos os presentes. Essa atividade não foi tumultuada e percebeu-se que os alunos conseguiram se organizar com tranquilidade. A seguir, na figura 1 , um resultado da atividade.

Figura 1 - A sexualidade de acordo com Ana Julia, Clotilde, Amorim, Billy, Tenyle, Jurema, Carlos e Jack. Data: setembro de 2010.

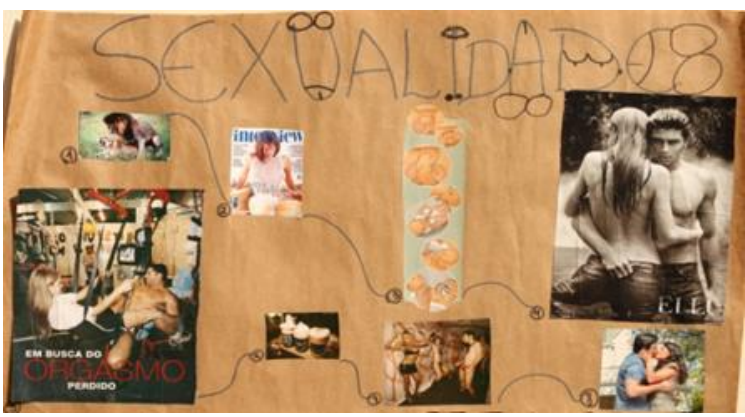

(Fonte: arquivo dos pesquisadores)

As diferentes representações construídas ainda evidenciam uma sexualidade reduzida a aspectos como juventude, a beleza do corpo e até mesmo ao sexo, como prática.

3. Panorama espontâneo - Na prática, os alunos, embasados nas discussões que já tinham feito com os colegas nas aulas anteriores, elaboraram três questões referentes à sexualidade e que poderiam ser objeto de estudos em aulas futuras. Nesse momento, também não seria necessário que se identificassem. A atividade resultou em um número satisfatório de questões, embora nem todos os alunos fizessem questionamentos. Apresentamos alguns resultados, explicitando questões simples e complexas: "O que faz uma pessoa ter atração por uma pessoa do mesmo sexo?"; "Como é transmitido o vírus da AIDS?"; "O que é orgasmo?"; 
Masturbação em excesso causa problemas, tanto para o homem quanto para a mulher?"; "Como funciona a pílula do dia seguinte?" Segundo Fourez (1997) esse momento é uma expansão do contexto do clichê e trata-se de etapa ainda bastante espontânea, enquanto não envolver especialistas. Em seguida, organizou-se a lista de especialistas participantes e as abordagens que seriam discutidas sem a presença dos mesmos. Considerou-se vantagens e inconvenientes em aprofundar determinados quesitos.

Foi elaborada, também, uma lista de caixas pretas e, a partir dos questionamentos, construiu-se a grande caixa preta: Sexualidade Humana, subdividida em uma caixa relacionada à dimensão biológica, outra, com enfoque sociocultural e uma terceira, com enfoque psicológico. As caixas pretas designam temas potenciais sujeitos ao estudo (entre os quais se elegerá os mais relevantes e do interesse dos alunos). Pôde-se observar que, no que diz respeito às concepções iniciais sobre sexualidade, há um entendimento do corpo como objeto de exploração comercial, considerando, em alguns casos, a sexualidade como sinônimo de prostituição. Durante os diálogos achou-se conveniente questionar a respeito de dois conceitos recorrentes nos questionamentos: prostituição e homossexualidade. Para o aluno Billy, por exemplo:

\footnotetext{
a prostituição é um tema muito forte nos meios de comunicação e entretenimento como a Internet e a TV. Quando falamos na palavra sexo ou sexualidade, nos vem à cabeça um ato, somente e preferencialmente erótico, selvagem, apelando para a malícia em coisas simples da natureza humana. 0 contexto prostituição vem da realidade social que vivemos em nosso mundo, mulheres ou mesmo homens que se prostituem por dinheiro fácil em busca da melhoria do padrão de vida.
}

Analisando concepções, percebeu-se que há curiosidade a respeito desses dois conceitos, possivelmente, influenciadas pelos meios de comunicação. Para os alunos, a prostituição não faz parte de seu contexto social ou desconhecem casos em suas histórias de vida. O que pareceu mais evidente é que a prostituição é aceitável quando as pessoas a utilizam como meio de sobrevivência. No que diz respeito ao tema homossexualidade alguns alunos se manifestaram: "antigamente era mais reprimido; é que agora está mais presente na sociedade, em novelas e filmes". Os meios de comunicação, mais especificamente as telenovelas nos horários nobres, apresentam personagens homossexuais, muitos, de forma declaradamente depreciativa. E é esse tipo de homossexual que parece incomodálos. Nos diálogos estabelecidos com o psicólogo, os alunos revelaram que tinham medo dos homossexuais. Uma aluna expôs: "eu sou bissexual, mas não fico dando em cima de qualquer pessoa". Observamos que a classe não mostrou sinais de rejeição ou espanto em relação à declaração da colega. Mas, ainda assim, ficou perceptível a natureza polêmica do tema.

4. Consulta a especialistas - é o momento em que o professor ou alunos decidem e oficializam o convite ao especialista para apresentar seus conhecimentos específicos, a partir dos temas que foram previamente definidos. Uma vez levantadas as caixas pretas a serem abertas, foram escolhidos os especialistas que fariam parte do projeto: uma professora de arte não integrante do quadro de professores e a professora de arte da escola ${ }^{2}$, um professor de marketing (área de propaganda e publicidade) e um psicólogo. Procurou-se não esquecer a metodologia com enfoque interdisciplinar e, para isso, foi necessário clareza dos objetivos que se queria alcançar com determinado conhecimento. A 
escolha dos especialistas foi decidida em função das questões elaboradas pelos alunos, uma vez que estavam relacionadas com diferentes áreas do conhecimento, como a biologia e a psicologia. Buscou-se uma série de possibilidades, porém, nem todos atenderam ao convite para participar. A especialista em arte foi professora na escola por muitos anos, e era conhecida por sua paixão pela história da arte. Seria interessante constatar como a arte, enquanto área do conhecimento poderia contribuir para a abertura da caixa preta sexualidade e como essa dimensão da cultura evoluiu ao longo dos tempos. O especialista em publicidade e propaganda foi escolhido por sua experiência como agente publicitário, enfocando como a mídia desperta a sexualidade precocemente. O especialista em psicologia foi uma indicação, a partir do seu trabalho com adolescentes sobre orientação sexual, prevenção e doenças sexualmente transmissíveis.

Os especialistas tomaram conhecimento das caixas pretas previamente organizadas, para que pudessem ter uma noção das dúvidas apresentadas pelos alunos e assim contribuir no aprofundamento do tema. Também foram orientados para não ultrapassarem cinquenta minutos. Conforme Fourez (1997) é importante limitar as contribuições, geralmente carregadas de informações. O tempo restante da aula seria utilizado para esclarecer dúvidas, promover um debate, fazer uma representação. Para o artigo, apresentamos a participação da especialista em arte.

5. Prática com a abertura de caixas pretas - nessa etapa, tendo clareza dos objetivos e objetos de estudos, com o foco na construção de modelos simples e promoção da alfabetização científica, pôde-se partir para a abertura das caixas pretas. A especialista em arte iniciou a etapa do projeto, desenvolvendo uma discussão a respeito da diferença entre sexualidade e sensualidade, pois nas representações iniciais percebeu-se que a sensualidade se reduzia a um corpo feminino exposto em capas de revistas.

A arte, por intermédio da pintura, da escultura e da arquitetura, registra momentos históricos. Conseguir ler, em representações artísticas, conceitos culturais e sua evolução através dos tempos torna-se interessante e esclarecedor, contribuindo para reflexões sobre preconceitos. Com esse objetivo, a especialista conduziu os alunos pelas imagens e relatos históricos, revelando como o conceito de sexualidade modificou-se com o passar dos acontecimentos, bem como o de sensualidade.

Nas aulas iniciais do projeto, emergiu o conceito de sexo como objeto de cobiça, de exploração financeira pela mídia, bem como pela sociedade. Também foi possível captar que, entre os alunos, permeia como consenso, a desvalorização moral e sexual da mulher em relação aos homens, que se preservam. A partir desse quadro, fez-se um resgate histórico do papel da mulher na sociedade. A especialista iniciou discorrendo sobre a diferença entre sensualidade e sexualidade. Sempre que abordava uma novo item, tentava obter dos alunos as primeiras impressões para que pudesse, então, esclarecer ou ponderar sobre os conceitos que estavam sendo estudados. Discorreu sobre sensualidade e sexualidade desde o período pré-histórico até a contemporaneidade, usando como referência o fenômeno "Lady Gaga". Iniciou com uma pintura rupestre e a partir daí fez um apanhado do momento histórico e de como representavam sua sexualidade. A seguir, passou pela cultura egípcia, quando o papel da mulher já não era mais de divindade, mas de igualdade, excetuando-se as escravas. $\mathrm{Na}$ sequência, viu-se o período do renascimento, século $X V$, momento em que a arte grega renasce, evidenciando a perfeição e a beleza. Na época, a mulher era 
apresentada coberta dos pés à cabeça, mas em pinturas a reverenciavam como mito e apresentavam-na sem roupa: o deus do céu (poder) era Urano e a deusa da terra (reprodução) era Gaia.

Já no século $X X$, a mulher busca seu espaço na sociedade, quer igualdade profissional, sexual, mas, muitas vezes, não encontra lugar para se estabelecer. A mulher luta para ter sua voz ouvida, suas necessidades consideradas, seus ideais respeitados e seu corpo visto como portador de inteligência e poder de decisão, não apenas como objeto para os serviços domésticos, para reprodução e para o prazer. A especialista optou trazer exemplos através de obras de Picasso, que chegou a representar aspectos sobre sexualidade.

O século XXI nos traz, no mundo artístico, "Lady-Gaga" que faz do corpo a sua propaganda, suas roupas extravagantes, ou ausentes, motivação e destaque na mídia. Sua postura é, por vezes, geradora de ataques pela imprensa. A forma de defender os homossexuais na sociedade, as atitudes e o vocabulário the conferiram o rótulo de hermafrodita, bissexual. O comportamento polêmico de Lady Gaga, para muitos, representa a arte atual, a moda, a música. Ao final da explanação, a especialista propôs um debate sobre sexualidade e sensualidade. A sala foi dividida em dois grupos: um discutiria a sensualidade e outro a sexualidade. A pergunta geradora da reflexão abrangeu desde a pré-história até os tempos atuais: "o que mudou de lá para cá"? A proposta gerou um interessante diálogo e Carla foi a primeira a se manifestar: "há uma falta de entendimento do que é sexualidade e sensualidade. Para ela sexualidade é ficar pelada em qualquer lugar, sensualidade é mais pertinente ao passado do que aos dias de hoje". Dave acrescentou: "A sexualidade é para ganhar dinheiro". A especialista interveio, dizendo que Dave havia acrescentado algo muito importante e perguntou: "a revista Playboy é produzida em função do quê?" Os alunos responderam: "dinheiro!". Nesse momento João levanta a mão e diz: "o sexo está sendo banalizado". Mike acrescenta: "ninguém obriga as pessoas a fazerem sexo, cada um faz por que quer." Então, a especialista intervém: "percebam, atualmente é tudo diversão, é o momento". Lara levanta a mão e contribui: "sexo, hoje em dia, é uma competição, não só na mídia". A aluna acrescenta: "um cara diz - peguei tantas meninas e outro diz - eu peguei tantas, o sexo não é mais 'valorizado'." Reforçou o termo "valorizado" com os dedos representando aspas. Gabi pede a palavra: "eu tinha um amigo e conversando, ele me disse que pediu o carro emprestado de outro amigo para levar uma menina, guria não sei para onde, depois voltou, pegou outra, assim pegou algumas." Para Bianca: "o cara não estava preocupado com os sentimentos das meninas". Fernanda: "o tratamento das mulheres é resultado, muitas vezes, de suas provocações, se ela sabe que para eles ela não é importante, por que se expõe?"

Como estava no final da aula, foi proposta uma atividade: a representação da própria sensualidade, numa folha de papel, por meio de colagens e palavras. Tudo o que havia mostrado pelas imagens, representava uma época: "como vocês percebem o tema na época atual?" Alessandra faz sua descrição:

Na minha opinião antigamente a sensualidade e a sexualidade não tinha praticamente nada a ver com o conceito de agora. Por exemplo; antigamente as mulheres podiam ser sensuais através de um olhar, um sorriso, ou até mesmo passando a mão nos cabelos. Mas ultimamente as mulheres e alguns 
As figuras escolhidas pelos alunos deixam transparecer como percebem a sexualidade e a sensualidade no século XXI: exposição do corpo nu, insinuação de contato sexual, provocação. Para Alessandra, perdeu-se o romantismo, a sutileza de pequenos e singelos atos. A sensualidade está na perfeição do corpo. Analisando as conclusões apresentadas, percebe-se que a sensualidade reduz-se a um corpo esbelto, coberto por roupas provocantes, preferencialmente, de "marca". No entanto, mostraram-se sensibilizados com a definição de sensualidade, como um ato de conquista, uma vez que a sensualidade pode estar presente na delicadeza dos gestos, independente da nudez.

A professora de biologia, juntamente com a de arte, chegaram à conclusão de que os alunos poderiam conhecer outras formas de representações. Era preciso tempo para revelar que há outras maneiras para representar o mesmo momento histórico pelo qual estão vivendo. Novamente a especialista em arte voltou à escola e, utilizando uma aula de arte da professora titular, com a participação da professora de biologia, puderam reorientar os alunos para que construíssem novos modelos. Esse momento foi muito rico, pois, como já foi comentado, a professora titular de arte trabalha muito bem atividades práticas e a especialista em história da arte aprecia muito o viés teórico. Importante ressaltar que as articulações entre o viés teórico e prático foram importantes para o processo de construção das representações pela arte. A especialista solicitou aos alunos que considerassem dois aspectos. O primeiro: a arte é uma forma de expressar um momento histórico; o segundo: o sexo não precisa ser banalizado. Sugeriu que poderiam expressar através de projeções surreais. Então, orientou sobre outras possibilidades de representação da sensualidade e sexualidade, sem cair na rotina das revistas. Trouxe como exemplo uma obra de Salvador Dali, intitulada "Persistência". Dali transportava seu problema para a arte, quando o pai obrigou-o a se afastar das mulheres, pois, na época, a sífilis era muito comum. Foi um processo traumático para Dali e, consequentemente, seu corpo respondia a esses traumas, e procurava em Freud respostas para a sua sexualidade. Foi proposta, então, a construção de uma representação surreal da sexualidade ou sensualidade nos tempos atuais. Para esta tarefa, agruparam-se para produzir, em uma folha de papel canson, uma pintura ou o projeto de uma escultura que contemplasse o tema, podendo usar lápis coloridos e tintas. Em seguida, orientou-os para que, na medida em que fossem chegando a uma conclusão sobre o desenho a ser projetado no papel, partilhassem com todos para, daí, concretizar a produção. A especialista destacou a contextualização histórica e a professora de arte auxiliou-os no desenvolvimento da atividade. A seguir (figura 2) apresentamos uma das produções, que mais se aproximou do surrealismo, de acordo com a especialista: 
Figura 2 - Uma escultura, apresentada por uma das equipes. Data: outubro de 2010.

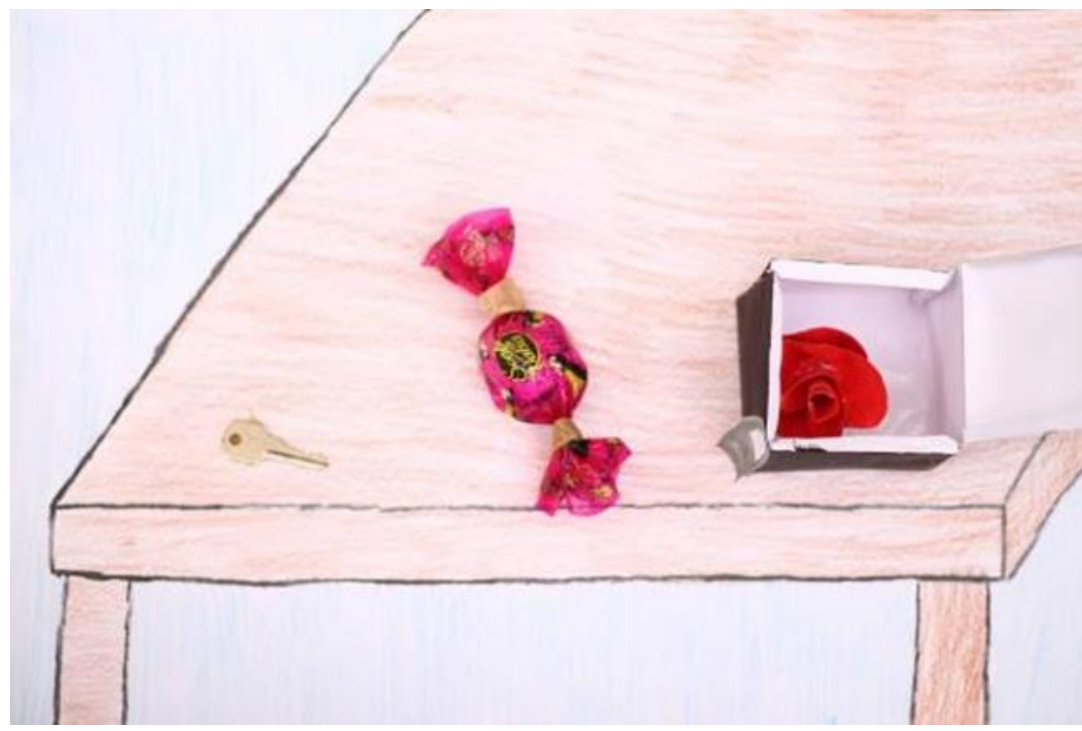

(Fonte: arquivo dos pesquisadores)

Conforme a equipe, a chave representa o homem, o bombom o desejo e a caixa com a flor, a vagina de uma mulher. Trata-se de uma escultura (pois apresenta três dimensões), em que a equipe mostra a virgindade como condição, por meio de uma caixa contendo uma flor. Segundo os alunos, essa flor é o que muitos homens querem, uma vez que ainda valorizam o fato de que a mulher, para ser companheira e mãe de seus filhos, deve ser virgem.

6. O produto final - na última semana de aula, foi solicitado aos alunos que produzissem um texto síntese sobre as ideias e conceitos estudados e, também, que elaborassem uma questão, a partir de um comando elaborado pela professora de biologia. Solicitou que contivesse conceitos trabalhados como sexualidade, sexo, sensualidade, reprodução, gravidez, doenças sexualmente transmissíveis, preconceito, etc. Os alunos também poderiam incluir outros termos em seus textos.

A respeito da atividade final, a grande maioria dos alunos conseguiu estabelecer conexões entre os diferentes conceitos, além de contextualizá-los adequadamente. Também foi possível perceber que algumas caixas pretas foram abertas, outras não, uma vez que foi solicitado que elaborassem uma pergunta sobre o tema e que gostariam de aprofundar. Conforme Fourez (1997) um tema pode ter concepções variadas e ao mesmo tempo apresentar intersecções e os alunos têm opção de fazer uso de caixas pretas sem conhecer seus conteúdos, ou de abrir outras caixas, complementando seu conhecimento. Foi possível observar repetições de questões já formuladas no início da proposta, mas também surgiram perguntas mais elaboradas e contextualizadas, confirmando um pressuposto de Fourez (1997) - o de que os alunos passam a fazer questões mais elaboradas em função das compreensões mais aprofundadas. Entretanto, também encontramos alunos que se deram por satisfeitos para o momento e não quiseram fazer mais nenhum tipo de questionamento: 
[...] sei que muitas caixas pretas foram abertas não só para mim, como para toda turma. Dúvidas foram tiradas, mas ainda existem muitas interrogações em nossas cabeças. Depois da biologia, vejo a psicologia como área mais importante de se abrir 'caixas pretas'.

Finalmente, "no início eu tinha algumas dúvidas, mas com o decorrer do projeto as minhas dúvidas foram esclarecidas." Quando solicitados para que fizessem uma avaliação da aplicação da metodologia, uma aluna assim escreveu:

\footnotetext{
O bom desse trabalho foi que não foram passados conhecimentos apenas sobre o ato, sexo, mas sim de outros temas que englobam a sexualidade e que são fundamentais. Sexualidade é um assunto muito importante para se passar aos adolescentes, [...]. A única crítica que tenho para fazer é em relação ao tempo, aos outros assuntos de biologia. Sei que foi excelente termos essas aulas, mas o problema foi perdermos três meses de aula de biologia (sobre o assunto que deveríamos ter aprendido nesses três meses).
}

Para Alessandra o desenvolvimento da proposta foi importante, porém: “[...] o problema foi perdermos três meses de aula de biologia (sobre o assunto que deveríamos ter aprendido nesses três meses)". Sua avaliação nos mostra, de certa forma, como a aula tradicional ainda está arraigada, uma vez que, ao final de contas, os conteúdos da biologia é que são importantes e o professor deve cumprir o programa definido. Assim como para muitos alunos é difícil mudar a lógica transmissão-recepção, imagina-se que também poderá ser um problema para muitos professores romperem paradigmas, deparar-se com o incerto, aspectos relacionados com o desenvolvimento da metodologia IIR. Ao se tratar de temas polêmicos em sala de aula, precisa-se cuidar para não omitir determinados aspectos julgados irrelevantes ou, até mesmo, que nos causa certo desconforto, mas que podem ser importantes para os alunos. Neste sentido, procurou-se desenvolver o tema evitando interpretações dúbias, procurando fazer com que os alunos refletissem melhor sobre suas concepções iniciais: a sexualidade não se reduz ao sexo, ao gênero, à reprodução, às doenças (FIGUEIRÓ, 2001). Sexualidade trata-se, também, da vida, liberdade, emoção, êxtase, amor, delicadeza, respeito e compartilhamento. Muitas vezes, no decorrer das aulas, alunos mostraram percepção reducionista e até mesmo alienada, o que levou à reflexão a respeito de como o processo de ensino em biologia pode contribuir para que essas percepções sejam ampliadas, tornadas objetivas, funcionais, geradoras de menor desconforto emocional.

\section{O QUE É POSSÍVEL CONCRETIZAR}

A proposta metodológica IIR objetiva minimizar problemas relacionados ao contexto disciplinar, uma vez que, mesmo sozinho, o professor pode dar a "arrancada" inicial, não necessitando de encontros extraclasses, com seus pares, para o planejamento. Para Maingain e Dufour (2008) há diversas oportunidades para se iniciar um projeto interdisciplinar: uma problemática, uma situação de vida, um dado da atualidade ou do ambiente, a preparação de uma viagem, por exemplo. Essa etapa, segundo Schmitz (2004) é fundamental para o professor que deseja aplicar a metodologia, que fará um levantamento cuidadoso dos recursos (materiais e humanos) a partir da definição do tema central, para evitar possíveis frustrações. Cabe ao professor fazer ajustes frente aos desafios não previstos para que a proposta se concretize. Segundo Maingain e Dufour (2008) deve-se 
aprofundar a capacidade de adaptação ao inesperado e promover negociações com os envolvidos.

No que diz respeito aos recursos humanos, Bettanin (2003) ressalta sobre a importância da escolha do especialista, sendo fundamental observar dois critérios: a situação somada ao projeto a ser desenvolvido e os objetivos escolares. Cabe ressaltar que delegar essa função aos alunos é interessante, entretanto faz-se necessária a supervisão do professor. No caso apresentado, muitas caixas surgiram e muitos especialistas poderiam estar envolvidos na abertura das mesmas: um farmacêutico (para as questões sobre anticoncepcionais), um médico (para as questões sobre gravidez ou DST), um professor de história (para questões sobre a história da sexualidade humana), um professor de arte (para questões sobre a sexualidade na arte). A diversidade de profissões que poderiam estar envolvidas foi grande, mas nem todos se mostraram disponíveis para o desafio.

Segundo Fourez (1997), a etapa "panorama espontâneo" é o momento de fazer escolhas convenientes. No presente projeto, foi possível e adequado contar com os especialistas em arte, em propaganda e publicidade, em psicologia, além da própria professora de biologia. Durante o panorama espontâneo deve-se planejar o número de aulas (aproximado, talvez) utilizado para a concretização da proposta. É importante que o professor esteja preparado e com tempo disponível para fazer paradas e replanejar, quando necessário.

O ponto de partida para iniciar uma proposta de natureza interdisciplinar acontece com a definição e a apresentação do tema. No caso da professora, a escolha do tema aconteceu em função do planejamento anual, tratando-se de uma sequência dos estudos sobre o núcleo e a divisão celular. Outros aspectos também foram levados em consideração: a emergência de um caso de doença venérea entre os alunos, gravidez precoce, entre outros. Em sala, apresenta-se o objeto de estudo e justifica-se o desenvolvimento da metodologia IIR com suas etapas, bem como alguns conceitos relacionados, como o de "caixas-pretas".

A etapa de organização das equipes não foi simples, uma vez que os alunos mostraram dificuldades em se agruparem e se organizarem entre seus pares. Porém, é necessário apresentar resultados ao grande grupo. Para Fourez (1997 p. 113) a investigação "parte da experiência cotidiana e, às vezes, revela profundos pré-conceitos. Ela reflete o que pensa um grupo sem formação especial."

A grande caixa preta e tema da investigação - a sexualidade humana deu origem a outras caixas, tomando-se por base as perguntas dos alunos. Em função do tempo exíguo, as caixas foram organizadas pela professora, sem a participação dos mesmos, no entanto, Bettanin (2003) argumenta que os alunos podem fazer essa classificação.

Na etapa Panorama espontâneo é conveniente uma análise de tensões que podem ocorrer na abertura de algumas caixas. No caso apresentado, por exemplo, optou-se por não envolver questões relacionadas à religião. No decorrer da história, a grande coibição religiosa levou à construção de ideias que passaram a fazer parte das representações dos indivíduos, muitas delas equivocadas.

Ressalta-se, também, que os especialistas convidados não devem se estender nas suas explicações. Trata-se de uma etapa importante, pois o especialista pode fazer um duplo papel: contribuir para abertura de caixas pretas e promover a criação de outras, ainda não pensadas. Em outras palavras, pode despertar o 
aprofundamento de questões ou ampliá-las. A etapa seguinte é chamada ida à prática. $\mathrm{O}$ especialista ou o professor irá trabalhar os conteúdos de maneira mais prática e, conforme o projeto em questão poderá ser feita uma visita de estudo, uma entrevista, assistir a um filme, proceder à leitura de textos para aprofundamento dos conhecimentos. Na próxima etapa, procura-se desenvolver, com maior rigor científico, o objeto de estudo, dando ênfase à disciplina base, no caso a biologia. Os conteúdos selecionados dependem do contexto do projeto, algumas vezes pode não dizer respeito às ciências naturais, mas às ciências humanas. Por isso, cabe ao professor estabelecer com clareza os objetivos.

A partir da etapa anterior (ida à prática), os alunos estão aptos para fazer uma síntese do que foi estudado até então: trata-se da esquematização global da temática. No caso, foi solicitado que produzissem um texto escrito e que envolvesse conceitos como sexualidade, sexo, DST, gravidez precoce, preconceitos, entre outros. A produção final foi concretizada por intermédio de folhetos explicativos e vídeos, onde os diversos saberes disciplinares convergiram, com suas devidas intersecções. Com as produções pôde-se perceber os entendimentos construídos pelos alunos, as relações conceituais e a utilização da linguagem científica, a partir de contextos criados pelos próprios alunos.

\section{CONSIDERAÇÕES FINAIS}

Um aspecto positivo da metodologia IIR, em relação a outras metodologias interdisciplinares é a sequência de etapas sugeridas para seu desenvolvimento. Fourez, com essa proposta, não quer construir uma receita pronta a ser seguida, mas atribui autonomia ao professor para fazer as devidas mudanças. A etapa zero não faz parte da metodologia proposta originalmente por Fourez, trata-se de uma adaptação sugerida aos professores por Schmitz (2004) cujo objetivo é operacionalizar a aplicação da metodologia, a organização das atividades nas situações de aprendizagem, os objetivos programáticos, os conteúdos e os métodos.

As etapas descritas não necessitam ser seguidas de forma linear; o professor pode saltar etapas ou pode voltar a uma etapa específica, conforme a necessidade da classe. Não existe um modelo fixo a ser seguido, pois cada classe apresenta suas particularidades, necessidades e diferentes questionamentos. Consequentemente as caixas pretas com seus objetos de estudo podem não ser os mesmos apresentados nesta experiência, logo, os especialistas também serão diferentes. Portanto o professor que aplicar a metodologia estabelece o tempo que necessita, limita os objetivos do projeto, mas para que a proposta seja interdisciplinar é importante que envolva, no mínimo, duas disciplinas. Evidencia-se, ainda, que os alunos devem trabalhar, preferencialmente, em equipes.

Entende-se que a aplicação da metodologia IIR pode promover a alfabetização científica, ou seja, desenvolve atitudes importantes como a reflexão fundamentada sobre questões importantes, além da crítica e a autonomia. Sugerese que o professor inicie com pequenos projetos e, na medida em que for obtendo confiança, proponha o desenvolvimento de projetos mais complexos. Reforça-se, com o apoio de Fourez (1997), Maingain e Dufour (2008) e Schmitz (2004) que um professor interessado na utilização da metodologia IIR, necessita ter clareza do seu papel de mediador, considerando-se aspectos como: organização, desafios, apoio, 
motivação, acompanhamento. A utilização da metodologia pressupõe que o professor abandone o ensino baseado na lógica transmissão-recepção. Os alunos passam a trabalhar em equipes, ação que pode desenvolver atitudes importantes como a tolerância, respeito à opinião do colega, organização, interação, negociação, decisão, entre outras. No caso aqui relatado, na medida em que o projeto foi tomando forma, os alunos passaram a se organizar em menos tempo, evoluindo nas discussões, diminuindo constrangimentos entre os pares.

No decorrer do processo, constatou-se que muitos alunos conseguiram constituir, de maneira muito satisfatória, uma relação entre a linguagem, pensamento e ação, aspecto que viabilizou a utilização dos conhecimentos científicos como instrumentos de operações qualitativamente superiores, como por exemplo, quando solicitados a apresentarem suas argumentações abalizadas em algum conhecimento científico já estudado, estabeleciam relações entre conceitos, além de buscar a utilização de linguagem mais adequada às situações. Esse aspecto foi evidenciado nas elaborações escritas, quando utilizavam corretamente instrumentos, entre outras ações. Na construção dos conhecimentos sobre sexualidade humana, os alunos, via trabalhos em equipes, por exemplo, foram conduzidos a pensar, analisar, planejar, organizar, sintetizar, enfim, exerceram um papel mais ativo em sala de aula. Evidentemente, o apoio da professora, que continuamente dirigia a atenção de todos para o conhecimento culturalmente organizado foi preponderante para o desenvolvimento da metodologia. Os conhecimentos científicos relacionados à sexualidade humana adquirem uma influência expressiva na construção da subjetividade quando deixam de ser elementos distantes e estranhos aos alunos e se transformam em instrumentos do pensamento sobre o mundo objetivo desses.

Os desafios também se estendem ao professor, uma vez que, como mediador, necessita organizar diferentes situações como o espaço físico da sala de aula, muitas vezes inadequado, o número elevado de alunos, a dificuldade dos mesmos em se organizarem, o tempo reduzido destinado às aulas e, evidentemente, a motivação do aluno e seu engajamento. 


\title{
The theme of human sexuality in high
} school: the interdisciplinary islands of rationality as a methodology in biology classes

\begin{abstract}
This study has been designed in order to identify the contributions of the methodology IIR in the process of scientific literacy starting from the study of the topic Human Sexuality by high school students in a public school in Brusque (SC). The lessons were videotaped, and subsequently analyzed. The results showed that students felt motivated to build their explanatory models resulting from the reflection, and also from the use of writing and collaborative participation with their peers. It is understood that the IIR can bring effective contributions to the learning of biology, as well as an expectation to the scientific literacy of the students.
\end{abstract}

KEYWORDS: Biology teaching. Sexuality. Interdisciplinarity. 


\section{NOTAS}

1 Os nomes dos alunos foram substituídos com o intuito de preservar suas identidades.

2 A professora de arte teve pequena participação dentro do seu horário com a turma: dedicou duas aulas para desenvolver as representações de sexualidade na perspectiva do surrealismo.

\section{REFERÊNCIAS}

ATKIN, J. M.; HELMS, J. Getting serious about priorities in science education. Studies in Science Education, n. 21, p.1-20, 1993.

BETTANIN, E. As Ilhas de Racionalidade na promoção dos objetivos da alfabetização Científica e Técnica. 2003. 169f. Dissertação ( Mestrado em Educação) - Universidade Federal de Santa Catarina, Florianópolis, 2003.

BRASIL. Parâmetros Curriculares Nacionais: Ensino Médio. Ministério da Educação. Secretaria Média e Tecnológica. Brasília: MEC/SEMTEC, 1998.

, Secretaria da Educação Média e Tecnológica . PCN+ Ensino Médio: Orientações Educacionais Complementares aos Parâmetros Curriculares Nacionais. Brasília: Ministério da Educação/ Secretaria de Educação Média e Tecnológica, 2002.

CASTRO, M.G.;ABRAMOVAY, M.;SILVA, L.B. da. Juventude e Sexualidade. Brasília: UNESCO, 2004

COLL, C.; MONEREO. Psicologia da educação virtual: aprender e ensinar as tecnologias da informação e da comunicação. Porto Alegre: Artmed, 2010.

EGYPTO, A. C. Orientação sexual na escola: Um projeto apaixonante. São Paulo: Cortez, 2003.

FENSHAM, P. J. Time to change drivers for scientific literacy. Canadian Journal of Science, Mathematics and Technology Education, Toronto, v. 2, n. 1, p. 9-24, jan. 2002,

FIGUEIRÓ, M. N. D. Educação sexual: retomando uma proposta, um desafio. 2. ed. Londrina: EDUEL, 2001. 
FOUREZ, G. A Construção das Ciências: introdução à filosofia e à ética das ciências. São Paulo: Editora UNESP, 1995.

G. Alfabetización científica y tecnológica. Acerca de las finalidades de la enseñanza de las ciencias. Buenos Aires: Ediciones Colihue, 1997.

. G. Crise no Ensino de Ciências? Investigações em Ensino de Ciências, v. 8, n. 2, p.109 -123, ago., 2003.

GIL-PÉREZ, D.; VILCHES, A. Contribution of Science and technological Education to Citizens' Culture. Canadian Journal of Science, Mathematics, \&Technology Education, , Toronto, v.5, n. 2, p. 253-263, 2005.

MAINGAIN, A. DUFOUR, B. A interdisciplinaridade em sentido estrito. In: FOUREZ, G. (Org.) Abordagens didácticas da interdisciplinaridade. Lisboa: Instituto Piaget, 2008.

MARINHO, A. M. S. A educação ambiental e o desafio da interdisciplinaridade. 2004. 117f. Dissertação (Mestrado em Educação) - Pontifícia Universidade Católica de Minas Gerais, Belo Horizonte, 2004.

SAYÃO, Rosely. Os problemas da informação sexual e o papel da escola. In: AQUINO, Julio Groppa. (Org). Sexualidade na escola: alternativas teóricas e práticas. 3 ed. São Paulo: Summus Editorial, 1997.

SANTOS, W. L. P. dos. Educação científica na perspectiva de letramento como prática social: funções, princípios e desafios. Revista Brasileira de Educação, Rio de Janeiro, v. 12, n.36, set./dez. p. 474-492, 2007.

SHAMOS, M. The myth of scientific literacy. New Brunswick: Rutgers University Press, 1995.

SCHMITZ, C. Desafio Docente: as Ilhas de Racionalidade e seus elementos Interdisciplinares. 2004. 260f. Dissertação (Mestrado em Educação Científica e Tecnológica). Universidade Federal de Santa Catarina, Florianópolis, 2004.

VILCHES, A.; SOLBES, J.; GIL- PÉREZ, D. Alfabetización científica para todos contra ciência para futuros científicos. Alambique, Barcelona, n.41, p. 89-98, 2004. 
Recebido: 20 fev. 2015.

Aprovado: 18 abri. 2016.

DOI: $10.3895 /$ rbect.v9n1.2054

\section{Como citar:}

IMHOF, A. M. Q.; SCHROEDER, E. O tema Sexualidade Humana no ensino médio: as Ilhas

Interdisciplinares de Racionalidade como metodologia em aulas de biologia. Revista Brasileira de Ensino de Ciência e Tecnologia, v. 9, n. 1, p. 277-300, jan./abr. 2016. Disponível em:

<https://periodicos.utfpr.edu.br/rbect/article/view/2054>. Acesso em: XXX.

\section{Correspondência:}

Ana Maria Quinoto Imhof

Avenida Primeiro de Maio, 112, 88353-200, Brusque, Santa Catarina

Edson Schroeder

Rua Antonio da Veiga, 140, 89012-900, Campus I, Blumenau, SC.

Direito autoral: Este artigo está licenciado sob os termos da Licença Creative Commons-Atribuição 4.0

Internacional.

\section{(c) (1)}

